\title{
Response of intertidal benthic macrofauna to migrating megaripples and hydrodynamics
}

\author{
Daphne van der Wal ${ }^{1, *}$, Tom Ysebaert ${ }^{1,2}$, Peter M. J. Herman $^{1,3}$ \\ ${ }^{1}$ NIOZ Royal Netherlands Institute for Sea Research, Department of Estuarine and Delta Systems, and Utrecht University, \\ PO Box 140, 4400 AC Yerseke, The Netherlands \\ ${ }^{2}$ Wageningen Marine Research, PO Box 77, 4400 AB Yerseke, The Netherlands \\ ${ }^{3}$ Deltares, PO Box 177, 2600 MH Delft, The Netherlands
}

\begin{abstract}
Migrating flow-transverse mesoscale intertidal bedforms (megaripples or dunes) may pose disturbance but may also provide heterogeneity in microhabitats to the inhabiting fauna. We investigated how the macrofauna community responds to these migrating intertidal bedforms, based on surveys in the Westerschelde estuary. Considering the entire estuary, lowand high-energy intertidal areas differed in macrofauna, and high-energy flat areas had a macrofauna community intermediate to those in low-energy flat areas and high-energy areas with megaripples. In megaripple areas on a polyhaline and a mesohaline tidal flat, the macrofauna community depended on hydrodynamics, morphodynamics, grain size, elevation and steepness of the megaripples. The relative importance of the environmental variables for structuring the macrofauna community differed for each site. Within the megaripples, conditions on crests, at flanks and in troughs were distinctly different: crests had more chl a and coarser sediment than troughs, while flanks had intermediate levels; troughs were higher in carbon and mud content than flanks and crests. The microhabitats supported a different macrofauna community but with a very large overlap in species. Troughs typically had higher species richness, while crests had higher densities of, in particular, (mobile) surface deposit feeders. Part of the macrofauna could benefit from the habitat heterogeneity within the megaripples, but the effect was relatively small. The distribution of macrofauna in the intertidal zone was particularly regulated by overall current velocities and bedform morphodynamics.
\end{abstract}

KEY WORDS: Macrofauna - Habitat partitioning · Bedforms · Megaripples · Hydrodynamics · Intertidal flat · Westerschelde

\section{INTRODUCTION}

Intertidal zones may accommodate large densities of benthic invertebrates (Ysebaert et al. 2003). However, the strong hydrodynamic forces, temperature fluctuations and desiccation result in few species specialized to cope with such stress (e.g. Elliott \& Quintino 2007). In the intertidal landscape, gradients in secondary production and macrofauna community composition may coincide with gradients in largescale hydrodynamics (e.g. Van Colen et al. 2010).
At the mesoscale, bedforms can develop through interaction with hydrodynamic forces. A large number of field and flume studies (see e.g. Reineck \& Singh 1980) have shown that at low current velocities (subcritical flow), a flat (lower-stage) plane with limited sediment movement (except for microscale ripples) is established. With increasing flow velocity, the bed is transformed into flow-transverse two-dimensional (2D) or three-dimensional (3D) mesoscale bedforms. These bedforms, with wavelengths of 0.6 to $20 \mathrm{~m}$ and wave heights of 0.06 to 
$2 \mathrm{~m}$, are here referred to as megaripples following Dalrymple et al. (1978) and Idier et al. (2004). They are regarded as a class of the more generic term subaquatic dunes (Ashley 1990, Passchier \& Kleinhans 2005). At very high flow rates, sheet flow results in a flat upper-stage plane. Eventually, at supercritical flow, antidunes are formed. Threshold flow conditions for the successive transitions of bed phases depend on sediment grain size and water depth (e.g. Southard \& Boguchwal 1973). The lateral migration rate of the megaripples/dunes also depends on flow conditions, sediment grain size and water depth (e.g. Southard \& Boguchwal 1973). Bed dynamics pose disturbance to the sediment (burial and erosion of sediment) and, hence, to the inhabiting benthic macrofauna (e.g. Hinchey et al. 2006).

A limited number of macrofaunal species can survive continuous disturbance of the sediment because these species show adaptation in behaviour, morphology or life history patterns (Shepherd 1983, Lytle \& Poff 2004, Hinchey et al. 2006, van der Wal et al. 2017). Crests and troughs of bedforms of varying size (ranging from ripples to megaripples, ridges and runnels, shoreface-connected ridges and sand waves) have been found to have different abiotic conditions (such as sediment grain size and organic matter content) but also to support different benthic communities (e.g. Barros et al. 2004, Baptist et al. 2006, van Dijk et al. 2012, Zonneveld et al. 2014, Markert et al. 2015). This habitat differentiation, induced by hydrodynamic forces, may counteract the negative effect of the stress of hydrodynamics and disturbance by dune migration on species richness (e.g. Gingold et al. 2011). The outcome of these antagonistic effects is, however, not known.

In this study, we investigated how hydrodynamics and disturbance by bedform migration affect intertidal benthic macrofauna distribution. We focused on 3 spatial scales. We tested whether different intertidal mesoscale bedforms (e.g. low- or high-energy flat areas, 2D and 3D megaripples) support a different macrofauna community, using data from tidal flats across the Westerschelde estuary. Subsequently, in field surveys on 2 tidal flats, we investigated if the macrobenthic community responds to hydrodynamic forces, megaripple morphology and/or disturbance by megaripple migration by comparing conditions and macrofauna among megaripples. We then investigated if macrofauna is able to benefit from the habitat differentiation within megaripples by testing whether environmental conditions and macrofauna differ between crests, flanks and troughs.

\section{MATERIALS AND METHODS}

\author{
Study sites
}

The study was conducted in the Westerschelde, a coastal plain estuary in the southwest of the Netherlands (Fig. 1) characterised by a multiple channel system with tidal flats. The estuary is macrotidal with a semi-diurnal tidal regime. It has a full salinity gradient and is typically turbid. The tidal flats of the Westerschelde as a whole are studied in the first part of the paper. Subsequently, 2 relatively sandy tidal flats were selected to study the bedforms in detail: Rug van Baarland, a tidal flat in the polyhaline zone of the estuary (at 2 sites referred to as BAN and BAS), and Plaat van Valkenisse, a tidal flat in the mesohaline part of the estuary (at a site referred to as VAL) (Fig. 1). Model predictions of salinity under mean river discharge conditions from a map produced by Rijkswaterstaat demonstrated a mean salinity of 20 for Site BAN, 20 to 21 for Site BAS, and 13 to 14 for Site VAL. Transects sampled at Sites BAN, VAL and BAS were all ebb dominated, except for flooddominated transects BAS21, BAS22 and BAS23 (Fig. 1).

\section{Macrofauna and conditions in intertidal bedforms across the estuary}

To assess the effect of bedforms on macrofauna in the entire Westerschelde, information on the geomorphology of the Westerschelde estuary was derived from maps provided by Rijkswaterstaat, Dutch Ministry of Infrastructure and the Environment. In these geomorphological maps, the form, reflection, colour, pattern and position of the intertidal area is obtained from false-colour aerial photographs (ca. 1:15000) and interpreted regarding morphology of the bed, substrate, dynamics and presence of epibenthic communities (saltmarsh, oyster and mussel beds). Classification procedures are described in de Jong (2012). In our study, of all geomorphological units occurring in the Westerschelde, we only considered the bare sandy or muddy tidal flats. Thus, hard substrate, peat, aeolian dunes, unvegetated areas in creeks, chenier shell ridges, mussel reefs, oyster reefs, water and saltmarsh and remaining classes were all omitted from further analyses (together labelled 'other' in Table 1). Table 1 lists the categories with the area they represent in the intertidal zone of the Westerschelde estuary. 
(a)

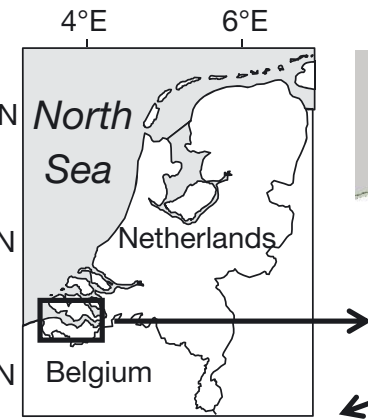

(b)
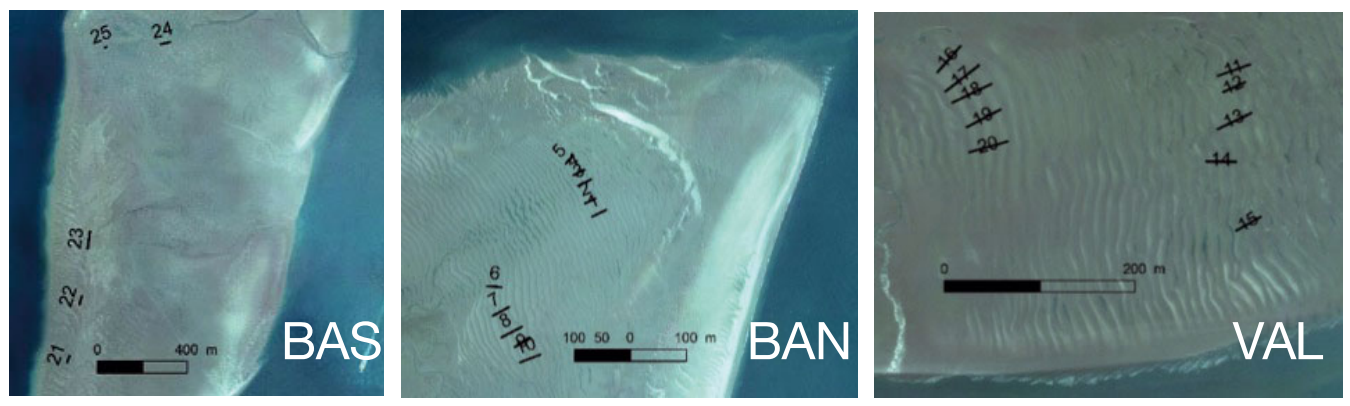

(c)

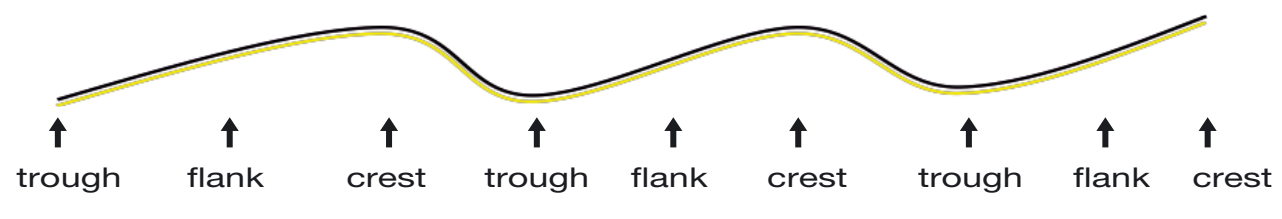

transect distance

(d)
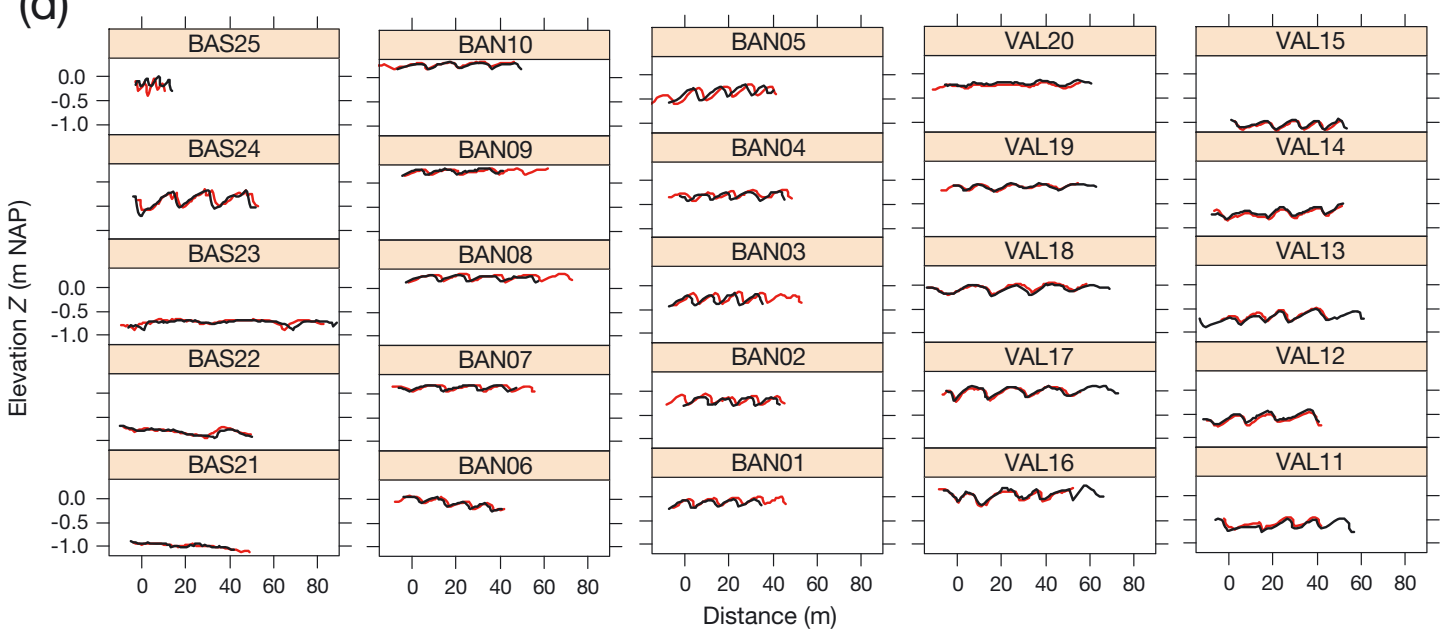

Fig. 1. (a) Location of the study sites and 25 transects, Westerschelde estuary, The Netherlands; (b) details of the intertidal area in a false-colour aerial photograph from 2011 (source: Rijkswaterstaat); (c) sampling scheme of a transect over a megaripple; (d) megaripple dynamics from differential GPS measurements in the middle (in black) and end (in red) of April 2012 (transects 1 to 20) and beginning (in black) and middle (in red) of September 2012 (transects 21 to 25) at sites Rug van Baarland (BAN, BAS) and Plaat van Valkenisse (VAL) (see 'Materials and methods: Study sites' for explanation). NAP: Normaal Amsterdams Peil, ca. mean sea level

Maps of current velocity (i.e. maximum current velocities during spring tide) were available from Rijkswaterstaat with $20 \mathrm{~m}$ pixel resolution from numerical modelling (ScalWest2000 model) based on bathymetry (elevation maps) from 2008, 2010, 2011 and 2012, calibrated with data from July 2000 (Kers et al. 2013).

Macrofauna data (2007 to 2012) were used from the Royal Netherlands Institute for Sea Research (NIOZ) 
Table 1. Geomorphological groups studied, with area represented in the intertidal zone of the Westerschelde estuary (obtained from geomorphological map of the Westerschelde estuary, 2011). 2D: two-dimensional; 3D: three-dimensional; $H$ : wave height; $L$ : wavelength. See 'Materials and methods: Macrofauna and conditions in intertidal bedforms across the estuary' for definition of geomorphological group 'Other'

\begin{tabular}{|llr|}
\hline $\begin{array}{l}\text { Geomorpho- } \\
\text { logical group }\end{array}$ & Description & $\begin{array}{r}\text { Area } \\
\left(\mathrm{km}^{2}\right)\end{array}$ \\
\hline P1a1 & Low-energy, flat, sandy tidal area & 25.95 \\
P1a2 & Low-energy, flat, muddy tidal area & 13.92 \\
P1b & Low-energy tidal area with low dunes $(H<0.25 \mathrm{~m}, L=10-25 \mathrm{~m})$ & 0.28 \\
P2a & High-energy tidal area with low dunes $(H<0.25 \mathrm{~m}, L>25 \mathrm{~m})$ & 3.38 \\
P2b1 & High-energy tidal area with 2D dunes $(H>0.25 \mathrm{~m})$ & 6.77 \\
P2b2 & High-energy tidal area with 3D dunes $(H>0.25 \mathrm{~m})$ & 4.01 \\
P2c & High-energy flat tidal area & 19.03 \\
& All other categories ('other') & 38.27 \\
& Westerschelde estuary entire intertidal zone $(2011)$ & 111.60 \\
\hline
\end{tabular}

database. In this data set, macrofauna sampling was stratified by ecotope (i.e. MONEOS Ecotopen data set for 2007 and 2008 and MWTL data set for 2009, 2010, 2011 and 2012). Within the ecotopes, samples were taken randomly (thus, without distinction of crests, flanks and troughs in mesoscale bed features). For the present study, we considered only samples collected in autumn to maximize comparability between samples. Sampling procedures were similar to those applied to the transect experiments (see 'Field sampling and measurements on megaripples along transects'). Of all samples, 705 samples were collected in one of the 7 geomorphological categories mentioned in Table 1 . As there was only 1 observation in P1b, the P1b group was also omitted from further statistical analyses.

In a GIS, polygon values from the geomorphological map and raster values from the current velocity and bathymetry maps were added to each of the sample points for 2008, 2010, 2011 and 2012. As no maps were available for 2007 and 2009, the 2007 and 2009 macrofauna data were linked to 2008 maps.

\section{Analysis of macrofauna and conditions in intertidal bedforms across the estuary}

A univariate analysis was performed to evaluate environmental conditions (current velocities and elevation) and macrofauna indices for each geomorphological group. Since the geomorphological groups had unequal variances for many of these variables (as tested with Levene's tests), non-parametric Kruskal-Wallis tests were performed; when significant differences were detected, a post hoc Dunn's test with Bonferroni correction for multiple comparisons was applied to identify homogeneous groups for that variable.

In addition, multivariate analyses were performed to test whether the geomorphological groups in the Westerschelde estuary accommodated a different macrofauna community. Multivariate analysis was carried out using the software package PRIMER (Plymouth Marine Laboratory, Clarke \& Warwick 2001), based on log-transformed biomass and density $[\ln (x+1)]$ of the macrobenthos species. To avoid ambiguity, the following rules were followed for the multivariate analysis. Of 170 taxa, unknown taxa and taxa that could not be identified at the genus level were deleted for the multivariate analyses. In cases where specimens of a genus were not all determined to the species level, taxa were merged to the genus level; spp. was added where multiple species were observed in 1 genus, while the species name was put in parentheses where only 1 species was identified within a genus. For example, Capitella and Capitella capitata were merged into a taxon named Capitella (capitata) in our data set. Finally, rare species, occurring in $1 \%$ or less of the stations, were deleted. After this procedure, 49 macrofauna taxa remained in the multivariate analyses. Similarity matrices were generated based on the Bray-Curtis similarity. Significance of differences ( $p \leq 0.05$ ) in the macrozoobenthos community between the geomorphological groups was formally tested using a 1-way ANOSIM in PRIMER. The distinction between groups was quantified by the non-parametric measure $R$, ranging from -1 to 1 . SIMPER analysis in PRIMER identified which species contributed most to the distinction of groups.

\section{Field sampling and measurements on megaripples along transects}

Intensive field campaigns were carried out in 2011 and 2012 on 2 tidal flats (Fig. 1). At both Rug van Baarland (BAN) and Plaat van Valkenisse (VAL), 2 areas were selected in high-energy megaripple areas, each with 5 transects, ca. $25 \mathrm{~m}$ apart, ranging from the high intertidal zone to the low intertidal 
zone, thus yielding 20 transects in total (Fig. 1b). Each transect was oriented in the direction of the dominant ebb flow and covered 3 sequences from trough to flank (i.e. stoss slope) to crest (i.e. 9 stations), starting with the trough by definition (Fig. 1c). Measurements at these 20 transects were carried out in June 2011 (i.e. just after the typical recruitment period of macrofauna), September 2011 (peak of macrofauna biomass) and April 2012 (just before main recruitment). For each campaign, a new set of 9 stations was defined along each transect. As the megaripples migrated, absolute position of the 9 stations along the transect and length of the transect thus varied between campaigns, whereas the position and orientation of the transect remained the same. In September 2012, 5 additional transects were sampled on the southern side of Rug van Baarland (BAS). These transects were wider apart (Fig. 1b) to capture a wide range of hydrodynamic conditions, ranging from the weakly dynamic transects BAS21 to BAS23 to the highly dynamic BAS25. Note that at Site BAS, not all transects were laid out in the direction of net dune migration; flanks could thus represent either the stoss slope or the lee slope (Fig. 1d).

At each station, 3 replicate cores with $8 \mathrm{~cm}$ diameter were collected up to a depth of $30 \mathrm{~cm}$; these replicates were taken some centimeters from each other. The material of the 3 cores was pooled and sieved with a $1 \mathrm{~mm}$ sieve. Material $>1 \mathrm{~mm}$ was stained with Bengal rose and fixed in formaldehyde and was used for the analysis of macrofauna (see van der Wal et al. 2008). Sediment was collected from the upper $3 \mathrm{~cm}$ of the surface for granulometric analysis and from the upper $1 \mathrm{~cm}$ for pigment analysis.

Currents were determined in the field for 2 springneap cycles using Nortek AquaDopps current velocity profilers (broadband $2000 \mathrm{kHz}, 10$ min pings) positioned at the first crest of a selection of transects, i.e. at BAN01, BAN03, BAN05, BAN06, BAN08 and BAN10 in June 2012, at VAL11, VAL13, VAL15, VAL16, VAL18 and VAL20 in April 2012 and at BAS21 to BAS25 in November 2012. From these measurements, the maximum current velocities during each tide were averaged over the 1 mo measurement period.

At the same selection of stations, a sequence of trough-flank-crest was measured with erosion pins of ca. $50 \mathrm{~cm}$ in length with a ring set flush to the surface. This ring moves downwards with erosion; the distance between the top of the pin and the ring is taken as a proxy for the deepest surface level in a period of time, denoted by $E$. Since some erosion pins were lost during the measurements, we used the erosion pins at the first crest to determine $E$. Both the hydrodynamic and erosion pin measurements were interpolated between transects for Sites BAN and VAL (e.g. values for transect BAN02 were obtained by averaging those of BAN01 and BAN03, see Fig. 3).

The absolute position and elevation $Z$ of all stations were measured at each campaign with a differential GPS. In addition, topographic profiles were measured with ca. $1 \mathrm{~m}$ interval. From these profiles, dune form parameters were derived, i.e. wavelength $L$ (distance from crest to crest, 2 replicates for each transect), wave height $H$ (height between successive trough and crest elements, 3 replicates for each transect) and dune steepness $H / L$ (ratio of transect-averaged $H$ and $L$ ). Morphodynamics were quantified from the topographic profiles (here linearly interpolated to a $0.1 \mathrm{~m}$ interval) measured ca. 2 wk apart. For each point on a transect, the absolute difference in elevation of 2 successive elevation measurements was calculated and averaged per transect as a measure of vertical sediment dynamics $|\mathrm{d} Z|$. The dune migration rate $|M|$ was calculated by comparing the lag of maximum cross-correlation of the sequential profiles in this 2 wk period (cf. Larcombe \& Jago 1996). The following periods were selected to calculate morphodynamics: 13 to 25 April 2011 (BAN01 to BAN05), 13 to 26 April 2011 (BAN06 to BAN10), 12 to 23 April 2011 (VAL11 to VAL15), 12 to 24 April 2011 (VAL16 to VAL20), 4 to 19 September 2012 (BAS21 to BAS25). The high-energy transect BAS25 had only moderate cross-correlation, while the erosion pins revealed substantial vertical change, suggesting either a change in dune shape or aliasing (migration distance exceeding the dune wavelength).

In the laboratory, sediment grain size samples of the transects were freeze dried, and the material was analysed using a Malvern laser particle sizer (Mastersizer 2000) to derive values for median grain size d50 $(\mu \mathrm{m})$ and mud (percentage particles $<63 \mu \mathrm{m}$ ). Organic carbon (\%) was determined for a selection of stations (see van der Wal et al. 2017 for methods). Pigments were extracted and quantified using HPLC, and chl a was identified by a comparison of peaks and retention times with available standards (see van der Wal et al. 2008).

Animals from macrofauna samples were identified in the laboratory under a dissecting microscope and counted at species level where possible. Density was expressed in individuals per square meter. Fragmented animals were counted as 1 , and only the heads of fragmented polychaetes were counted. Animals were dried at $80^{\circ} \mathrm{C}$ for $2 \mathrm{~d}$, then at $100^{\circ} \mathrm{C}$ for $1 \mathrm{~d}$ and then were ashed for $2 \mathrm{~h}$ at $580^{\circ} \mathrm{C}$ to determine 
biomass (ash-free dry weight, in $\mathrm{mg} \mathrm{m}^{-2}$ ). Biomass of bivalves was based on a regression line of dry weight of individuals per length class. Feeding traits (i.e. surface deposit feeders, deposit feeders, suspension feeders, omnivores, carnivores/predators, herbivores and other) of taxa were obtained from the NIOZ database. To calculate taxon richness $S$ for each sample (as a relative measure of biodiversity), the genus level was only counted when the species level was not present, and the family level was only counted when the species or genus level was not present in a sample. To meet or approach homogeneity of variance, values for macrobenthic density and biomass were transformed following $\ln (x+1)$ and denoted by lnden or lnbio, respectively.

\section{Analysis of macrofauna and conditions among megaripples (transects)}

Multivariate analysis of the macrofauna community of the transect data was performed following the same protocol as with the MWTL data from the entire intertidal zone of the Westerschelde. In total, 92 taxa were recorded in the macrofauna community data. After pretreatment of the macrofauna community data (see explanation in previous paragraph), 36 taxa remained for density and 35 taxa remained for biomass for transect data in the multivariate analyses. The 10 most common taxa were shown to make up the bulk of total macrofauna density and biomass (see Fig. 4). Similarity matrices were generated based on the Bray-Curtis similarity index in PRIMER. Conditions (elevation, chlorophyll content, mud content, median grain size, height of the megaripple, wavelength of the megaripple, steepness of the megaripple, elevation dynamics, maximum erosion at the crest, migration rate of the megaripple and current velocity) were averaged per transect and normalized per site (BAN, VAL, BAS). A Spearman rank correlation with permutation test (99 permutations, $\mathrm{p}<0.05$ significance level) to correlate the transect-averaged macrofauna community with the environmental variables, applying a Euclidean distance matrix, and a stepwise search of environmental variables (BVSTEP routine in PRIMER) were applied for each site separately.

\section{Analysis of macrofauna and conditions at troughs, crests and flanks of megaripples}

The differences in macrofauna community among bedform elements (trough, flank and crest) were studied using the multivariate data in PRIMER. A 2-way crossed ANOSIM with the factors transect and megaripple position (trough, flank, crest) was applied to the Bray-Curtis similarity matrix based on the station data sampled in September to test the relevance of dune position when taking into account the differences between transects (for Sites BAN, VAL and BAS). An ANOSIM was also applied to all station data with the factors seasons (where available) and position, to test the relevance of megaripple position relative to that of season, for each site separately.

The differences in macrofauna and environmental conditions among bedform elements were further tested with univariate general mixed modelling (lme in R). With the data collected in September, we tested whether the variation in macrobenthos and environmental variables depended on the categorical (fixed-effect) predictor position (3 levels: trough, flank, crest), with the random effect transect nested in site. With the seasonal data collected at Sites BAN and VAL only, we tested whether the variation in macrobenthos and environmental variables depended on the categorical (fixed-effect) predictors season (3 levels: June 2011, September 2011 and April 2012) and position (3 levels: trough, flank, crest), and their interaction, and the random effect transect nested in site.

\section{RESULTS}

\section{Macrofauna and conditions in intertidal bedforms across the estuary}

Data from the entire intertidal zone of the Westerschelde estuary encompassed a wide range of hydrodynamics and bedforms. An increase in macrofauna density, biomass and species richness with decreasing current velocity and increasing elevation was apparent, but with considerable scatter (Fig. 2). Lowenergy flat areas (groups P1a1 and P1a2, see Table 1) had the lowest current velocities and the highest average log-transformed density, log-transformed biomass and taxon richness of macrofauna (Table 2). Based on modelled current velocities, the highenergy flat areas are positioned between the lowenergy flat areas and the high-energy dune areas. Thus, these areas likely do not represent upper-stage plane conditions. Corresponding to their intermediate hydrodynamic regime, the high-energy flat areas also accommodate an intermediate macrofauna richness. 


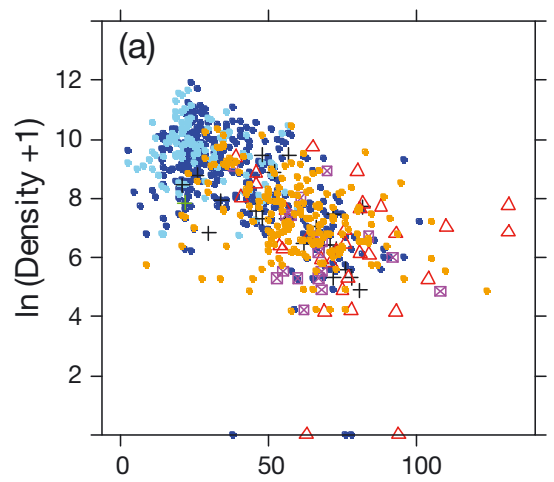

Max. current velocity, model $\left(\mathrm{cm} \mathrm{s}^{-1}\right)$

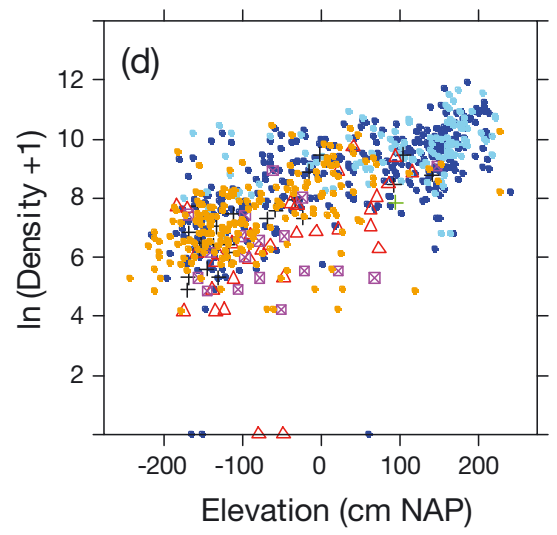

P1a1_LE_Flat_Sandy
P1a2_LE_Flat_Muddy

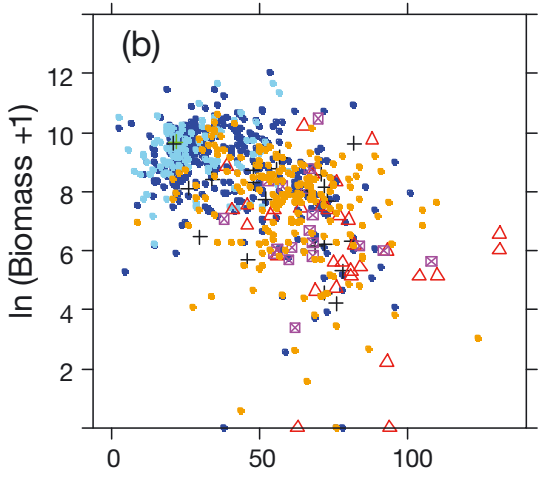

Max. current velocity, model $\left(\mathrm{cm} \mathrm{s}^{-1}\right)$

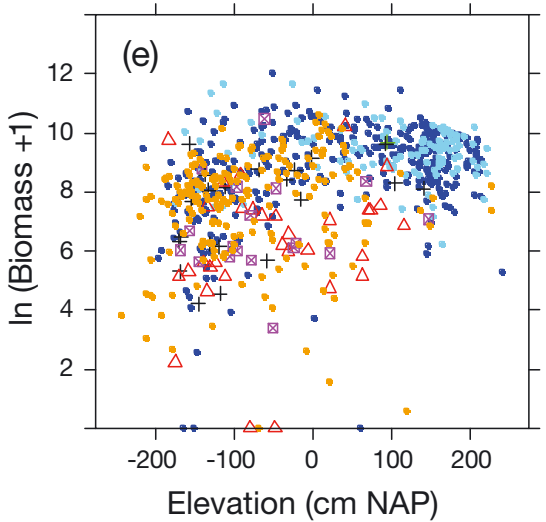

P1b_LE_2D_H $<25 \mathrm{~cm}+$ P2a_HE_2D_H $<25 \mathrm{~cm}+$

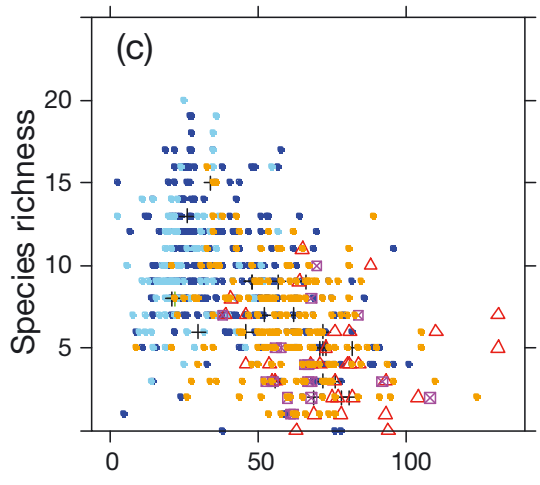

Max. current velocity, model $\left(\mathrm{cm} \mathrm{s}^{-1}\right)$

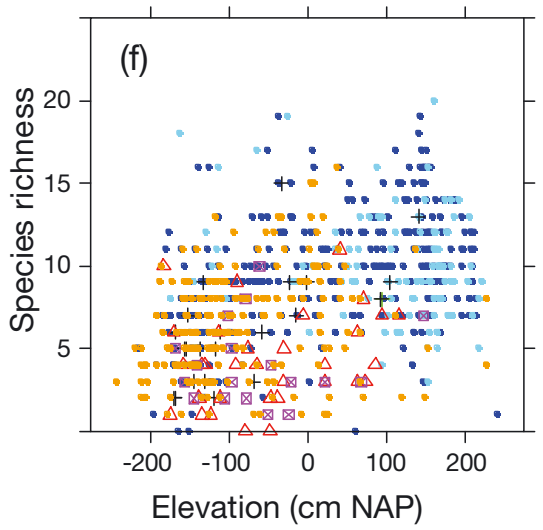

P2b1_HE_2D_H $>25 \mathrm{~cm} \triangle$ P2b2_HE_3D_H $>25 \mathrm{~cm} \quad \otimes$ P2c_HE_Flat

Fig. 2. Log-transformed density, biomass and species richness of macrofauna (autumn 2007 to 2012) against modelled maximum current velocities (spring tide) and elevation for selected classes of geomorphology (bare intertidal mudflats and bare intertidal sandflats only) in the entire intertidal zone of the Westerschelde estuary. Geomorphological groups are defined in Table 1. NAP: Normaal Amsterdams Peil, ca. mean sea level; LE: low energy; HE: high energy

Log-transformed density, biomass and species richness differed significantly among geomorphological groups (Kruskal-Wallis tests, $\mathrm{p}<0.05)$. However, the gradual reduction in macrofauna density, biomass and species richness in high-energy areas (going from flat areas to low (gently undulating) dunes, to high 2D dunes, to high 3D dunes) was typically not significant among bedforms (Kruskal-Wallis and post hoc Dunn's tests for multiple comparisons; Table 2), although species richness differed between highenergy flat areas and high-energy 2D dunes.

Differences in macrofauna community between the 5 geomorphological groups were significant (ANOSIM, global $\mathrm{R}=0.211, \mathrm{p}=0.001$ ); all pairs also significantly differed in community, except for the low-energy flat sandy or muddy areas (P1a1 versus $\mathrm{P} 1 \mathrm{a} 2, \mathrm{p}>0.05)$, high 2D or 3D dunes (P2b2 versus P2b1, p > 0.05) and high-energy high 2D dunes or high-energy low (gently undulating) dunes (P2b1 versus $\mathrm{P} 2 \mathrm{a}, \mathrm{p}>0.05)$. The low-energy muddy group (P1a2) stood out most in community composition compared to the 3 high-energy groups (all pairs $\mathrm{R}>$ $0.8, \mathrm{p}=0.001)$. In the 2 low-energy groups, Corophium (spp.), Heteromastus filiformis and Limecola balthica contributed most to the similarity within a group (Table 2). In the 2 high-energy groups with high dunes, Bathyporeia (spp.) and H. filiformis contributed most to the similarity. Both P2a (high-energy undulating) and P2c (high-energy flat) had an intermediate benthic community. They significantly differed in community from each other $(\mathrm{R}=0.285, \mathrm{p}=$ 0.001): P2C contained higher abundances of $H$. filiformis, Bathyporeia (spp.), L. balthica, Corophium (spp.), Pygospio elegans and Peringia ulvae but less abundance of Scoloplos armiger and Nephtys (spp.), together contributing to over $50 \%$ of the dissimilarity 
Table 2. Mean \pm SE of variables of geomorphological groups, ranked from high to low macrofauna taxon richness. Homogeneous groups in univariate analyses (non-parametric Bonferroni-corrected Dunn's post hoc test) and multivariate community analyses (ANOSIM comparisons, based on log-transformed densities and biomass) are denoted by superscript letters. Taxa that contribute at least $10 \%$ to the similarity in a geomorphological group are ranked from large to small contribution in the multivariate SIMPER analyses (based on log-transformed densities). 2D: two-dimensional; 3D: three-dimensional; H: wave height; NAP: Normaal Amsterdams Peil, ca. mean sea level; $V_{\text {max }}$ : maximum current velocity; $Z$ : elevation

\begin{tabular}{|c|c|c|c|c|c|c|}
\hline \multirow[t]{2}{*}{ Variable } & $\begin{array}{l}\text { P1a2: } \\
\text { Low energy, } \\
\text { flat, muddy } \\
(\mathrm{n}=109)\end{array}$ & $\begin{array}{l}\text { P1a1: } \\
\text { Low energy, } \\
\text { flat, sandy } \\
(\mathrm{n}=330)\end{array}$ & $\begin{array}{l}\text { Geomorpho } \\
\text { P2c: } \\
\text { High energy, } \\
\text { flat } \\
\text { (n = 193) }\end{array}$ & $\begin{array}{c}\operatorname{logical} \text { group } \\
\text { P2a: } \\
\text { High energy, } \\
\text { 2D, } H<25 \mathrm{~cm} \\
(\mathrm{n}=22)\end{array}$ & $\begin{array}{c}\text { P2b1: } \\
\text { High energy, } \\
\text { 2D, } H>25 \mathrm{~cm} \\
(\mathrm{n}=32)\end{array}$ & $\begin{array}{c}\text { P2b2: } \\
\text { High energy, } \\
\text { 3D, } H>25 \mathrm{~cm} \\
(\mathrm{n}=18)\end{array}$ \\
\hline & $\longrightarrow$ & & 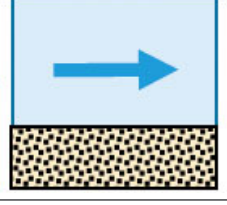 & 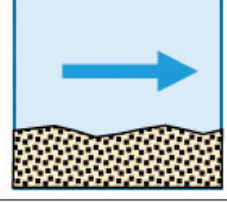 & 7 & 32 \\
\hline $\begin{array}{l}\text { Condition } \\
V_{\max } \text { modelled }\left(\mathrm{cm} \mathrm{s}^{-1}\right) \\
Z(\mathrm{~m} \text { NAP) }\end{array}$ & $\begin{array}{l}27.3 \pm 1.2^{\mathrm{a}} \\
0.95 \pm 0.10^{\mathrm{a}}\end{array}$ & $\begin{array}{l}39.9 \pm 1.1^{b} \\
0.33 \pm 0.69^{b}\end{array}$ & $\begin{array}{l}59.29 \pm 1.3^{\mathrm{c}} \\
-0.81 \pm 0.63^{\mathrm{c}}\end{array}$ & $\begin{array}{l}58.73 \pm 3.9^{\mathrm{c}, \mathrm{d}} \\
-0.78 \pm 0.20^{\mathrm{c}}\end{array}$ & $\begin{array}{l}76.38 \pm 4.0^{\mathrm{d}} \\
-0.47 \pm 0.16^{\mathrm{c}}\end{array}$ & $\begin{array}{l}66.72 \pm 3.7^{\mathrm{c}, \mathrm{d}} \\
-0.63 \pm 0.19^{\mathrm{c}}\end{array}$ \\
\hline $\begin{array}{l}\text { Macrofauna } \\
\left.\text { Density (ind. } \mathrm{m}^{-2}\right) \\
\ln (\text { Density }+1)\left(\text { ind. } \mathrm{m}^{-2}\right) \\
\text { Biomass }\left(\mathrm{mg} \mathrm{m}^{-2}\right) \\
\ln (\text { Biomass }+1)\left(\mathrm{mg} \mathrm{m}^{-2}\right) \\
\text { Species richness } \\
\text { Community }\end{array}$ & $\begin{aligned} 16363 & \pm 1734 \\
9.590 & \pm 0.0967^{\mathrm{a}} \\
22306 & \pm 2017 \\
9.312 & \pm 0.0877^{\mathrm{a}} \\
9.73 & \pm 0.30^{\mathrm{a}} \\
\mathrm{a} & \end{aligned}$ & $\begin{aligned} 12827 & \pm 867 \\
8.654 & \pm 0.0911^{\mathrm{b}} \\
13466 & \pm 955 \\
8.730 & \pm 0.0893^{\mathrm{b}} \\
9.46 & \pm 0.20^{\mathrm{a}} \\
\mathrm{a} & \end{aligned}$ & $\begin{aligned} 4668 & \pm 444 \\
7.329 & \pm 0.0947^{\mathrm{c}} \\
3516 & \pm 397 \\
7.503 & \pm 0.129^{\mathrm{c}} \\
6.43 & \pm 0.22^{\mathrm{b}} \\
\mathrm{b} & \end{aligned}$ & $\begin{aligned} 3923 & \pm 947 \\
7.141 & \pm 0.284^{\mathrm{c}} \\
2822 & \pm 818 \\
7.443 & \pm 0.336^{\mathrm{c}} \\
6.32 & \pm 0.73^{\mathrm{b}, \mathrm{c}} \\
\mathrm{c} & \end{aligned}$ & $\begin{aligned} 2523 & \pm 1000 \\
6.368 & \pm 0.391^{\mathrm{c}} \\
2250 & \pm 662 \\
6.197 & \pm 0.404^{\mathrm{c}} \\
4.31 & \pm 0.49^{\mathrm{c}} \\
\mathrm{c}, \mathrm{d} & \end{aligned}$ & $\begin{aligned} & 3329 \pm 1930 \\
& 6.335 \pm 0.330^{\mathrm{c}} \\
& 1535 \pm 606 \\
& 6.775 \pm 0.370^{\mathrm{c}} \\
& 4.06 \pm 0.59^{\mathrm{b}, \mathrm{c}} \\
& \mathrm{d}\end{aligned}$ \\
\hline Characteristic taxa & $\begin{array}{l}\text { Heteromastus } \\
\text { filiformis, Coro- } \\
\text { phium (spp.), } \\
\text { Nereis, Hediste } \\
\text { diversicolor, } \\
\text { Limecola balthica, } \\
\text { Pygospio elegans }\end{array}$ & $\begin{array}{l}\text { L. balthica, } \\
\text { P. elegans, } \\
\text { H. filiformis } \\
\\
\text {, }\end{array}$ & $\begin{array}{l}\text { H. filiformis, } \\
\text { L. balthica, } \\
\text { Bathyporeia } \\
\text { (spp.), Coro- } \\
\text { phium (spp.) }\end{array}$ & $\begin{array}{l}\text { L. balthica, } \\
\text { Scoloplos } \\
\text { armiger, } \\
\text { Nephtys (spp.) }\end{array}$ & $\begin{array}{l}\text { Bathyporeia } \\
\text { (spp.), } \\
\text { H. filiformis, } \\
\text { Nephtys (spp.) }\end{array}$ & $\begin{array}{l}\text { Bathyporeia } \\
\text { (spp.), } \\
\text { H. filiformis }\end{array}$ \\
\hline
\end{tabular}

Table 3. Mean, minimum and maximum of transect-averaged variables of macrofauna and environment for each site, including macrofauna density and biomass, taxon richness $S$, elevation $Z$, chl a content of the sediment, mud content and median grain size d50 of the sediment, height $H$, length $L$ and steepness $H / L$ of the megaripple, migration rate of the megaripple $|M|$, elevation variation $|\mathrm{d} Z|$, maximal vertical erosion $E$ at the crest and average maximum current velocity $V_{\text {maxavg. }}$ NAP: Normaal Amsterdams Peil, ca. mean sea level; BAN, BAS: Rug van Baarland sites; VAL: Plaat van Valkenisse site

\begin{tabular}{|c|c|c|c|c|c|c|c|c|c|c|}
\hline \multirow{2}{*}{ Transect } & \multirow{2}{*}{ Unit } & \multicolumn{3}{|c|}{$-\operatorname{BAN}(\mathrm{n}=10)-$} & \multicolumn{3}{|c|}{$\longrightarrow$ VAL $(\mathrm{n}=10)$} & \multicolumn{3}{|c|}{$-\operatorname{BAS}(\mathrm{n}=5)$} \\
\hline & & Mean & Min. & Max. & Mean & Min. & Max. & Mean & Min. & Max. \\
\hline Density & ind. $\mathrm{m}^{-2}$ & 1162 & 911 & 1526 & 5751 & 1711 & 9185 & 4304 & 778 & 6659 \\
\hline Biomass & $\mathrm{mg} \mathrm{m}^{-2}$ & 5729 & 2136 & 10384 & 4956 & 3241 & 8002 & 19715 & 1504 & 35328 \\
\hline$S$ & & 6.40 & 5.22 & 7.67 & 7.92 & 5.78 & 8.67 & 8.38 & 4.67 & 10.11 \\
\hline$Z$ & $m$ NAP & -0.06 & -0.38 & 0.24 & -0.41 & -1.06 & 0.02 & -0.61 & -0.97 & -0.19 \\
\hline Chl a & $\mu g g^{-1}$ & 8.37 & 4.59 & 12.50 & 7.43 & 5.17 & 9.11 & 2.77 & 1.09 & 6.39 \\
\hline Organic carbon & $\%$ & 0.06 & 0.05 & 0.07 & 0.07 & 0.06 & 0.09 & 0.06 & 0.03 & 0.08 \\
\hline Mud & $\%$ & 0.08 & 0.00 & 0.49 & 1.43 & 0.69 & 2.20 & 2.48 & 0.11 & 5.81 \\
\hline $\mathrm{d} 50$ & $\mu \mathrm{m}$ & 249 & 241 & 257 & 220 & 206 & 232 & 221 & 206 & 245 \\
\hline$H$ & $\mathrm{~m}$ & 0.19 & 0.16 & 0.24 & 0.24 & 0.19 & 0.28 & 0.16 & 0.02 & 0.35 \\
\hline$L$ & $\mathrm{~m}$ & 10.61 & 7.86 & 15.03 & 14.27 & 10.03 & 17.79 & 15.76 & 4.05 & 29.28 \\
\hline$H / L$ & $\mathrm{~m} \mathrm{~m}^{-1}$ & 0.02 & 0.01 & 0.03 & 0.02 & 0.01 & 0.02 & 0.02 & 0.00 & 0.05 \\
\hline$|M|$ & $\mathrm{m} \mathrm{d}^{-1}$ & 0.14 & 0.01 & 0.22 & 0.05 & 0.01 & 0.08 & 0.11 & 0.00 & 0.24 \\
\hline$|M|$ & m (in ca. 2 wk) & 1.75 & 0.10 & 2.60 & 0.59 & 0.15 & 0.90 & 1.64 & 0.00 & 3.60 \\
\hline$|\mathrm{d} Z|$ & m (in ca. 2 wk) & 0.05 & 0.02 & 0.10 & 0.03 & 0.02 & 0.05 & 0.05 & 0.01 & 0.11 \\
\hline$E$ & cm (in ca. 2 wk) & 5.63 & 3.30 & 9.60 & 3.50 & 0.00 & 6.20 & 11.28 & 3.00 & 31.90 \\
\hline$V_{\text {maxavg }}$ & $\mathrm{cm} \mathrm{s}^{-1}$ & 57.08 & 53.35 & 59.57 & 59.70 & 55.08 & 63.76 & 63.21 & 53.88 & 81.95 \\
\hline
\end{tabular}



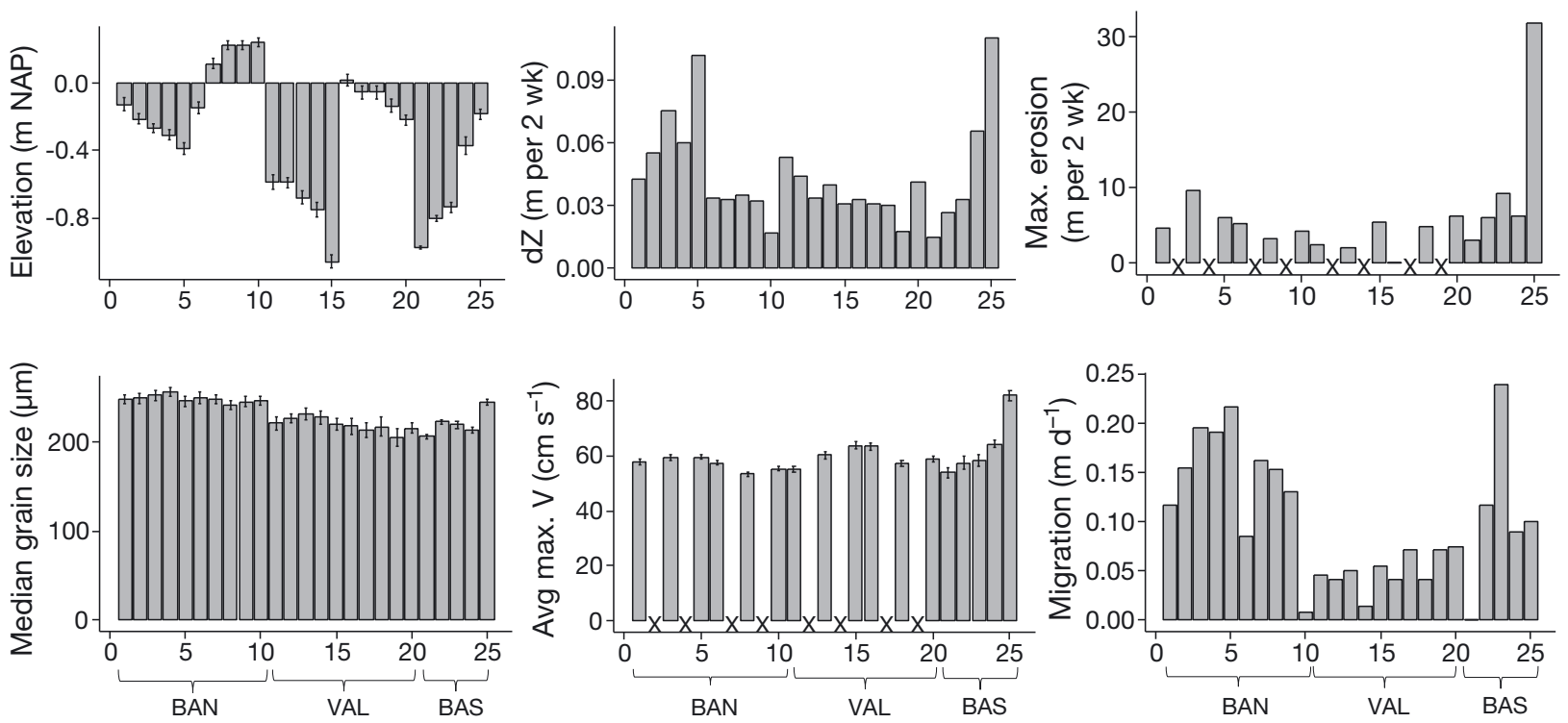

Fig. 3. Characterisation of the hydrodynamics and morphodynamics for each transect. Error bars show SE. No data are available for transects marked with X. See 'Materials and methods' for explanation of variables. dZ: elevation variation; NAP:

Normaal Amsterdams Peil, ca. mean sea level; BAN, BAS: Rug van Baarland sites; VAL: Plaat van Valkenisse site

between the groups. Similar results in macrofauna communities between geomorphological groups were obtained based on the log-transformed biomass of taxa (ANOSIM, global $\mathrm{R}=0.204, \mathrm{p}=0.001$; Table 2).

\section{Macrofauna and conditions among megaripples (transects)}

The transects over megaripples at the tidal flats sampled in September (either 2011 or 2012) encompassed a range of conditions (Table 3, Fig. 3). Transect-averaged wave heights of the bedforms varied between 0.02 and $0.25 \mathrm{~m}$, and average wavelengths of the bedforms varied between 4.05 and $29.28 \mathrm{~m}$ (Table 3).

The macrofauna community in September differed among the samples at the 3 sites (BAN, VAL and BAS) (ANOSIM, global $\mathrm{R}=0.664, \mathrm{p}=0.001$ based on $\log$ densities and global $\mathrm{R}=0.649, \mathrm{p}=0.001$ based on log biomass of taxa) (see also Fig. 4). Therefore, correlations between transect-averaged variables and transect-averaged macrofauna community were studied per site. Current velocity explained the macrofauna community best at Site BAN (BVSTEP analysis, $\rho=0.773$ based on lnden and $\rho=0.678$ based on lnbio). Steepness of the bedform $H / L$ explained the macrofauna community best at Site BAS ( $\rho=0.927$ based on lnden and $\rho=0.964$ based on lnbio). A combination of conditions explained the community best at Site VAL $(\rho=0.724$ based on lnden included elevation, mud content, bedform migration rate and current velocity and $\rho=0.674$ based on lnbio included elevation, mud content and migration rate).

\section{Macrofauna and conditions at troughs, crests and flanks of megaripples}

Considering the macrofauna community sampled in September using multivariate analyses, with the factors transect and position (trough, flank and crest), there is a pronounced difference in community composition between transects across all positions (ANOSIM, global $\mathrm{R}=0.667, \mathrm{p}=0.001$ for $\log$ density and global $\mathrm{R}=0.641, \mathrm{p}=0.0001$ for log biomass). Across all transects, there is also a significant effect of position (global $\mathrm{R}=0.2, \mathrm{p}=0.001$ for log density and $\mathrm{R}=0.189, \mathrm{p}=0.001$ for $\log$ biomass). Pairwise comparisons between positions were all significant (all $\mathrm{p}<0.05$ ). Taxa typically contributed very little $(<10 \%)$ to the dissimilarity between troughs and crests, crests and flanks, and flanks and crests; only L. balthica and Arenicola spp. each contribute over $10 \%$ to the dissimilarity between positions, based on biomass.

A 2-way crossed ANOSIM on the factors season and position separately for Site BAN and Site VAL based on log densities of taxa revealed that the macrobenthic community varied more between sea- 


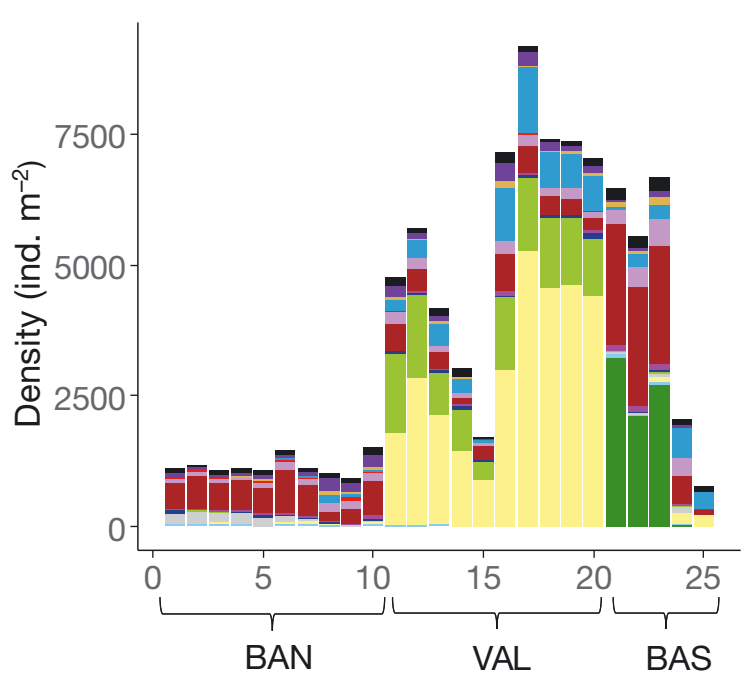

Aphelochaeta marioni Arenicola spp. Bathyporeia spp.

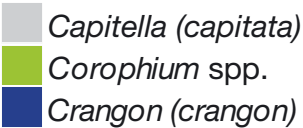

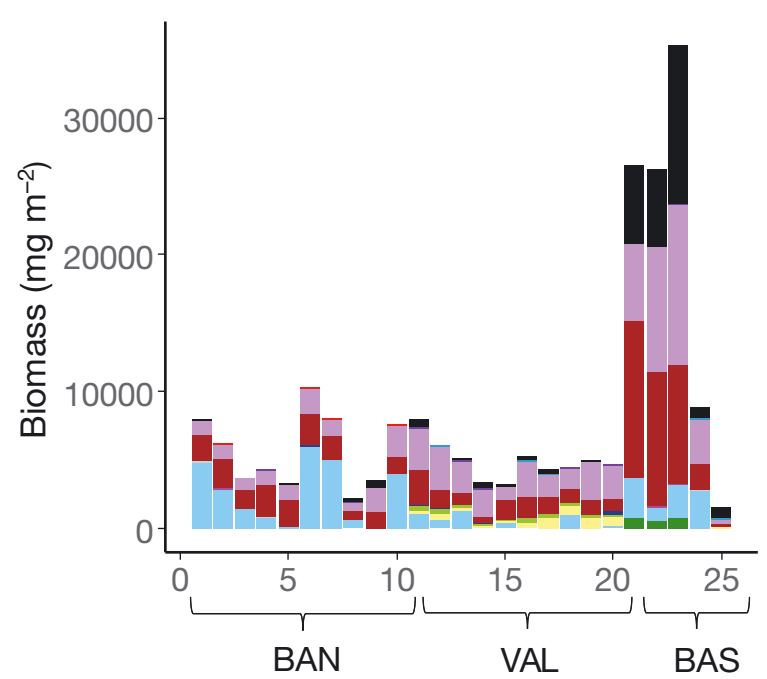

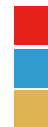

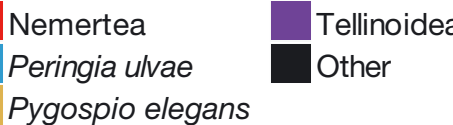

Fig. 4. Total density and biomass of macrofauna, with distinction of the 10 most common macrofauna taxa, at Sites BAN (September 2011), VAL (September 2011) and BAS (September 2012), averaged per transect. BAN, BAS: Rug van Baarland sites; VAL: Plaat van Valkenisse site

Table 4. Mixed-effects modelling of geoposition (trough, flank, crest) (with random factor transect nested in site) on conditions and macrofauna for September data for Sites BAN, VAL and BAS. Tukey contrasts for significant $(p<0.5)$ position effects are based on multiple comparisons of means. d50: median grain size of the sediment; df: degrees of freedom; geo: geoposition; NAP: Normaal Amsterdams Peil, ca. mean sea level; BAN, BAS: Rug van Baarland sites; VAL: Plaat van Valkenisse site; Z: elevation

\begin{tabular}{|c|c|c|c|c|c|c|}
\hline Variable & $\mathrm{n}$ & Effect & $\mathrm{df}$ & $F$ & $\mathrm{p}$ & Post hoc Tukey's test (geo) \\
\hline \multicolumn{7}{|l|}{ Condition } \\
\hline \multirow[t]{2}{*}{$Z$ (m NAP) } & 225 & (Intercept) & 1,198 & 4.896 & 0.0281 & \\
\hline & & Geo & 2,198 & 332.989 & $<0.0001$ & Crest $>$ flank $>$ trough \\
\hline \multirow{2}{*}{ Mud (\%) } & 225 & (Intercept) & 1,198 & 3.566 & 0.0604 & \\
\hline & & Geo & 2,198 & 26.656 & $<0.0001$ & Trough highest \\
\hline \multirow[t]{2}{*}{$\mathrm{d} 50(\mu \mathrm{m})$} & 225 & (Intercept) & 1,198 & 597.395 & $<0.0001$ & \\
\hline & & Geo & 2,198 & 213.396 & $<0.0001$ & Crest $>$ flank $>$ trough \\
\hline \multirow[t]{2}{*}{ Chl a $\left(\mu g g^{-1}\right)$} & 225 & (Intercept) & 1,198 & 13.597 & $3 \times 10^{-4}$ & \\
\hline & & Geo & 2,198 & 41.649 & $<0.0001$ & Crest $>$ flank $>$ trough \\
\hline \multirow[t]{2}{*}{ Carbon (\%) } & 126 & (Intercept) & 1,110 & 322.994 & $<0.0001$ & \\
\hline & & Geo & 2,110 & 6.361 & 0.0024 & Trough highest \\
\hline \multicolumn{7}{|l|}{ Macrofauna } \\
\hline \multirow[t]{2}{*}{$\ln \left(\right.$ Density + 1) (ind. $\left.\mathrm{m}^{-2}\right)$} & 225 & (Intercept) & 1,198 & 305.852 & $<0.0001$ & \\
\hline & & Geo & 2,198 & 10.850 & $<0.0001$ & Crest highest \\
\hline \multirow[t]{2}{*}{$\ln ($ Biomass +1$)\left(\mathrm{mg} \mathrm{m}^{-2}\right)$} & 225 & (Intercept) & 1,198 & 971.314 & $<0.0001$ & \\
\hline & & Geo & 2,198 & 2.855 & 0.06 & \\
\hline \multirow[t]{2}{*}{ Species richness } & 225 & (Intercept) & 1,198 & 157.519 & $<0.0001$ & \\
\hline & & Geo & 2,198 & 9.326 & $1 \times 10^{-4}$ & Trough highest \\
\hline \multicolumn{7}{|l|}{ Macrofauna feeding traits } \\
\hline $\begin{array}{l}\ln (\text { Density deposit feeders }+1 \text { ) } \\
\left(\text { ind. } \mathrm{m}^{-2}\right)\end{array}$ & 225 & $\begin{array}{l}\text { (Intercept) } \\
\text { Geo }\end{array}$ & $\begin{array}{l}1,198 \\
2,198\end{array}$ & $\begin{array}{c}1050.548 \\
2.421\end{array}$ & $\begin{array}{c}<0.0001 \\
0.0915\end{array}$ & \\
\hline \multirow{2}{*}{$\begin{array}{l}\ln (\text { Density surface deposit feeders }+1 \text { ) } \\
\left(\text { ind. } \mathrm{m}^{-2}\right)\end{array}$} & 225 & (Intercept) & 1,198 & 52.932 & $<0.0001$ & \\
\hline & & Geo & 2,198 & 4.333 & 0.0144 & Crest $>$ trough \\
\hline $\begin{array}{l}\ln (\text { Density suspension feeders + 1) } \\
\left(\text { ind. } \mathrm{m}^{-2}\right)\end{array}$ & 225 & (Intercept) & 1,198 & 12.154 & 0.0006 & \\
\hline
\end{tabular}



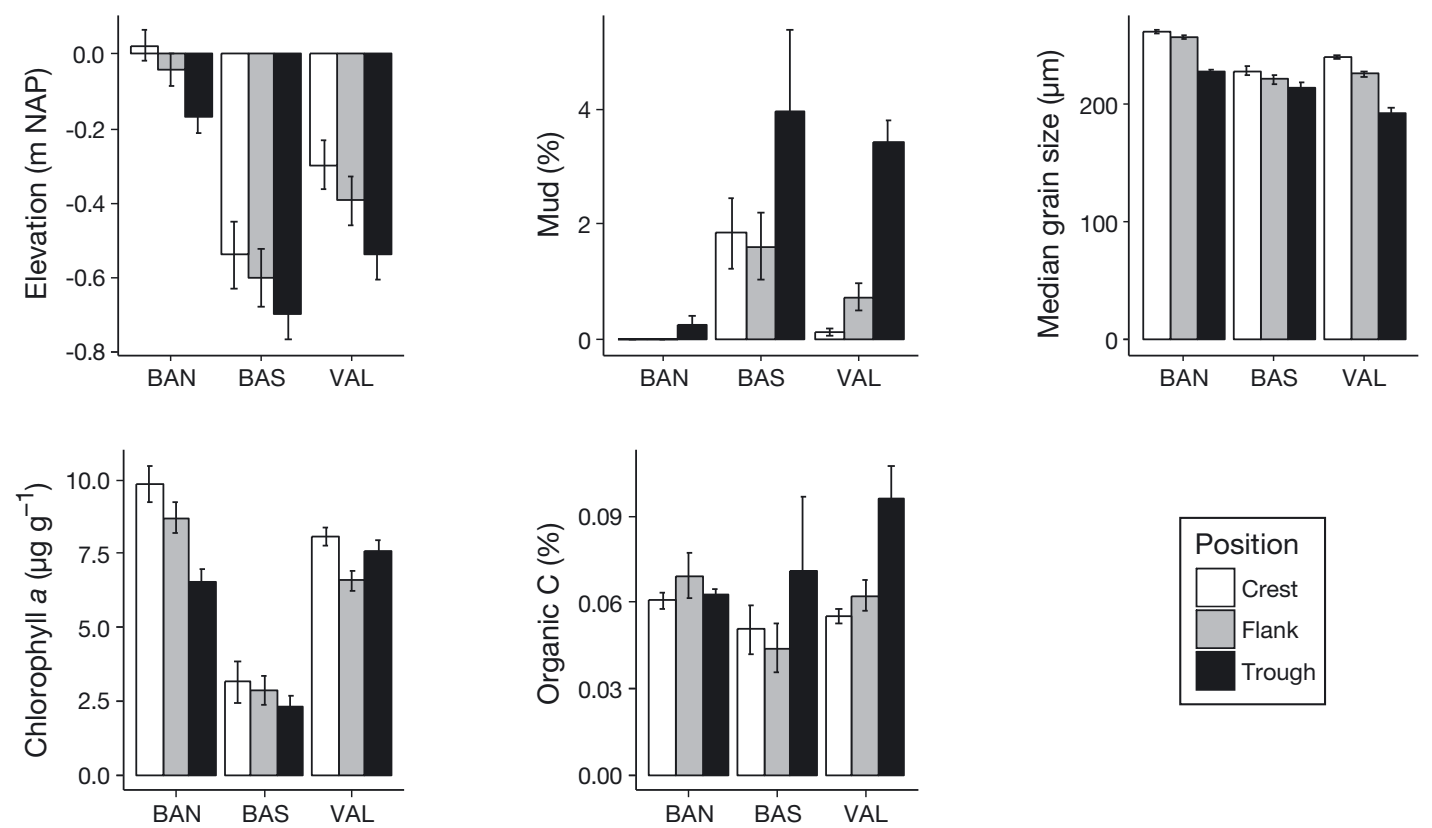

Fig. 5. Environmental conditions (average and SE) on crest, flank and trough of megaripples (September data only). NAP: Normaal Amsterdams Peil, ca. mean sea level; BAN, BAS: Rug van Baarland sites; VAL: Plaat van Valkenisse site
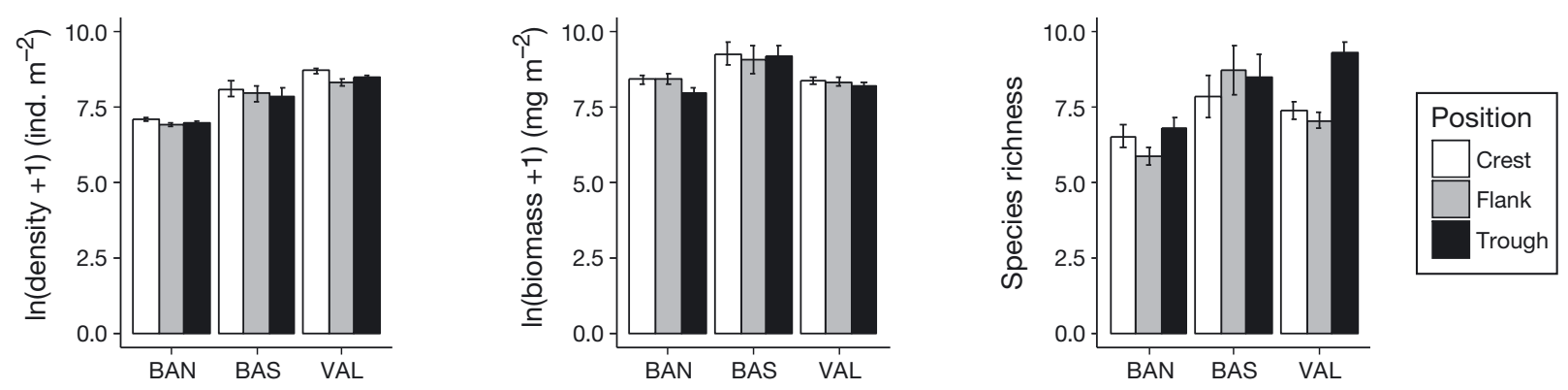

Fig. 6. Macrofauna (average and SE) on crest, flank and trough of megaripples (September data only). BAN, BAS: Rug van Baarland sites; VAL: Plaat van Valkenisse site

sons (global $\mathrm{R}=0.338, \mathrm{p}=0.0001$ for Site BAN and global $\mathrm{R}=0.369, \mathrm{p}=0.0001$ for Site VAL) than between troughs, flanks and crests (global $\mathrm{R}=0.055$, $\mathrm{p}=0.0001$ for Site BAN and global $\mathrm{R}=0.085, \mathrm{p}=$ 0.0001 for Site VAL). Similar results were obtained for analyses based on log biomass (all global tests $\mathrm{p}<$ 0.05). At Site BAS (September sampling available only), differences between troughs, flanks and crests were not significant, neither based on densities (global $\mathrm{R}=0.002, \mathrm{p}=0.398$ ) nor biomass (global $\mathrm{R}=-0.004$, $\mathrm{p}=0.490$ ) of taxa.

Univariate mixed-effects modelling of the September data showed that sediment grain size was highest at the crest, while mud and carbon content were highest in the troughs (Table 4, Fig. 5). For Sites BAN and VAL, seasonal data are available (Table S3 in the Supplement at www.int-res.com/articles/suppl/m585 p017_supp.pdf). Chlorophyll was highest at the crest, whereas, again, mud and carbon content were highest in the trough, and grain size was lowest at the troughs of megaripples. Thus, conditions were generally distinctly different for troughs, flanks and crests. For the macrofauna sampled in September at the 3 sites (BAN, VAL and BAS), log-transformed density was found to be highest on the crest, while taxon richness was highest in the troughs (Table 4, Fig. 6). Surface deposit feeders were higher on the crest than in the troughs. Suspension feeders were almost absent in all transects and positions. Only in the very weakly dynamic transects at site BAS was there a considerable number of suspension feeders; these transects also had the highest diversity. Of the common taxa highlighted in Fig. 4, the univariate analyses indicated no significant spatial segrega- 
tion in Aphelochaeta marioni, Arenicola sp., Capitella (capitata), H. filiformis, L. balthica and Nemertea. Crangon (crangon) had significantly higher densities in the trough. Tellinoidea and Eteone spp. had higher densities in the trough than at the flank. P. elegans had higher densities in the trough than on the crest. In contrast, Bathyporeia spp. had highest densities on the crest, and Corophium spp. had higher densities on the crest than at the flank (Tables S1 \& S2 in the Supplement). For Sites BAN and VAL, taking into account all seasons, mixed-effects models also showed segregation of macrofauna within the transects (Table S3). The log-transformed total density of macrofauna was lowest at the flanks, while species richness was higher in the troughs than at the flanks. Log-transformed density of deposit feeders was highest in the troughs in June only.

\section{DISCUSSION AND CONCLUSIONS}

This study examined the role of hydrodynamics and morphodynamics in the structuring of intertidal benthic macrofauna. At the spatial scale of the tidal flats across an entire estuary, the poorest macrofauna communities (in terms of abundance, biomass and species richness) were found in highly dynamic areas with regular or irregular mesoscale bedforms, while the richest macrofauna communities were found in weakly dynamic areas, and highly dynamic flat areas were intermediate. This could largely be explained by a negative effect of current velocities and a positive effect of elevation on macrofauna. However, there was a superimposed effect of morphodynamics: highly dynamic flat areas had a different macrofauna community than highly dynamic areas with low or high 2D dunes, under similar current velocities and elevation.

Our estuarine-wide intertidal survey revealed that Heteromastus filiformis occurred in all bare intertidal areas (but was most abundant in the low-energy areas), Limecola balthica occurred in all but the most mobile sites and Corophium spp. typically occurred in the sandy low-energy sites. Bathyporeia spp. occurred in all but the muddy sites. The macrofauna communities in the megaripples of the Westerschelde were typically dominated by taxa adapted to a mobile environment. The ability of small-scale post-settlement dispersal of macrofauna would increase the resilience of species to react to the mobile environment (e.g. Armonies \& Hellwig-Armonies 1992, Günther 1992, Zühlke \& Reise 1994, Norkko et al. 2001, Grantham et al. 2003, Davidson et al. 2004). In field and laboratory experiments, responses of macrofauna species to burial vary as a function of their mobility, living position and tolerance of anoxic conditions (Hinchey et al. 2006, Bolam 2011). Epifaunal suspension feeders, borers and adult deep-burrowing siphonate suspension feeders generally are unable to escape more than $1 \mathrm{~cm}$ of burial (Kranz 1974). Indeed, in our study sites, epifaunal suspension feeders were rare, and infaunal suspension feeders were only abundant in the weakly dynamic zones at Site BAS. Sedentary deposit feeders, such as Aphelochaeta marioni are also known to be sensitive to burial (Bolam 2011), explaining their low abundance at Sites BAN and VAL and the highly dynamic Sites BAS24 to BAS25 and higher abundance at Sites BAS21 to BAS23. In the Wadden Sea, Zühlke \& Reise (1994) found a reduction of Arenicola marina, Pygospio elegans, Scoloplos armiger and oligochaete species in response to sediment mobility, while for example Capitella capitata remained unaffected. In contrast, Peringia ulvae is known to exhibit good migration capability, notably in sediments with low organic content (Bolam 2011). Kranz (1974) established that Macoma nasuta was able to escape sedimentation at a rate of $>2 \mathrm{~cm} \mathrm{~h}^{-1}$, and Ensis directus could escape at rates of $>6 \mathrm{~cm} \mathrm{~h}^{-1}$, while burrowing rates of these species were order(s) of magnitude larger. Bathyporeia spp. has a (surface) feeding behavior, high mobility on the sediment, frequent benthic-pelagic exchange and breeding habit that allows survival in dynamic conditions, as confirmed in our study.

The transect study also revealed significant differences in community between the sites studied in detail. This may partly be explained by differences in salinity. For example, Arenicola marina is largely restricted to the polyhaline zone (Ysebaert et al. 2003), as found at Sites BAS and BAN. For some other species, an explanation for the site differences is less obvious, e.g. for Bathyporeia spp. A spatial scale effect, where the community within transects and within sites is more similar than that among sites, may also have contributed to the differences between, particularly, Sites BAN and VAL.

When comparing among megaripples within each of the 3 sites, the macrofauna community was affected by strong current velocities, morphodynamics (e.g. migration rate), coarse sediments, elevation and steepness of the megaripples $(H / L)$. Megaripple steepness may be proportional both to the depth of burial and erosion and to the frequency of disturbance and may therefore be a good proxy for disturbance. Factors best explaining the macrofauna community differed for each site. This may have been 
caused by the limited range in some of the environmental variables in these highly dynamic areas (e.g. current velocities at Sites BAN and VAL) and possibly by the community traits of each site (e.g. more surface deposit feeders at Site VAL).

Within the bedforms, the influence of small-scale differences in habitat can have a pronounced effect on the distribution of food resources and macrofaunal species distributions. Ramey et al. (2009) demonstrated that small-scale ripple troughs (sand ripples 5 to $15 \mathrm{~cm}$ in height) had higher zoobenthos densities, but diversity was lower than on crests. Van Dijk (2012) studied large sand waves (ca. $190 \mathrm{~m}$ in length, ca. $2.6 \mathrm{~m}$ in height, migration rate ca. $2 \mathrm{~m} \mathrm{yr}^{-1}$ ) in the North Sea: the ridges were characterised by lowdensity, low-diversity communities, while the troughs were characterised by high-density, high-diversity communities, and the flanks were in between. Baptist et al. (2006) also observed a richer macrofauna in the troughs than on the crests of subtidal sand waves in the North Sea. Markert et al. (2015) found distinct macrofaunal communities at the troughs, flanks and crests of shoreface-connected ridges in the German Wadden Sea, while Zonneveld et al. (2014) found species segregation on a ridge and runnel system in British Columbia, Canada. Similarly, spatial segregation due to microhabitat heterogeneity was demonstrated in nematode communities in runnel and sand bar systems (Gingold et al. 2011, Maria et al. 2013).

In our study, we examined intertidal megaripples that were intermediate in size between the microscale ripples and the large-scale subtidal sand waves. Within such megaripples, we showed a clear segregation in conditions among crests, flanks and troughs: crests of megaripples had higher chlorophyll levels and coarser sediment than troughs, while flanks had intermediate levels. In addition, troughs were higher in carbon and mud content than flanks and crests. In our study, migration rates of the megaripples were on average $0.1 \mathrm{~m} \mathrm{~d}^{-1}$ (as measured over a $2 \mathrm{wk}$ interval), i.e. almost 20 times faster than those observed by van Dijk et al. (2012) in sand waves of the North Sea bed, however with less potential burial by deposition of sand, as our megaripple wave heights were smaller.

We expected that mobile species would be best adapted to benefit from habitat differentiation. Levinton \& Kelaher (2004) argued that localized inputs of resources would lead to strong spatial heterogeneity in macrofauna, but when mobile species dominate, such patches are rapidly equalized (as they would exhaust the patches and move on). In our dynamic megaripples, animals have to cope with a constant rearrangement of resources as a result of bedform migration. In addition, they have to avoid or escape burial or erosion resulting from lateral bedform migration. We found the highest biodiversity of macrofauna in troughs of megaripples, while total density was highest on the crest. Troughs, flanks and crests also supported a different macrofauna community, but there was a very large overlap in species. As in Baptist et al. (2006), segregation of the community composition between crests, flanks and troughs was less important than changes in community composition over the seasons. The mobile carnivore Crangon (crangon) and Tellinoidea bivalves were most abundant in troughs, which may have benefited from the local water or food resources. Mobile surface deposit feeding amphipod crustaceans such as Bathyporeia spp. preferred the crests. Grant (1981) also found greater numbers of burrowing crustaceans in ripple crests than troughs, at least in the lower intertidal zone. Some abundant species that did not show spatial segregation, such as $H$. filiformis and C. capitata, may have been able to cope with some degree of disturbance, as was also clear from the estuary-wide survey, but did not seem to benefit from the habitat differentiation induced by the bedforms.

We conclude that macrofauna species could only marginally benefit from the habitat differentiation in megaripples, resulting in a very weak spatial segregation in the macrofauna community and a slight increase in the biodiversity of macrofauna in the troughs of megaripples. Overall current velocities and morphodynamics appear to be the most important factors for the macrofauna community.

Acknowledgements. D.v.d.W., T.Y. and P.M.J.H. contributed to the sampling design; D.v.d.W. analysed the data and wrote the manuscript; P.M.J.H. contributed to statistical methods. Macrobenthos samples were collected, determined and counted by the Monitor Taskforce of NIOZ. We thank Vincent Escaravage in particular for contributing to the coordination of the macrofauna collection and analysis and for delivering the macrofauna data. Lennart van IJzerloo contributed to the field measurements. We thank Marco Houtekamer, Lennart van IJzerloo, Peter van Breugel, Juriaan Brasser and Coby van Zetten of NIOZ for HPLC and grain size analyses of samples. Marco Schrijver (Rijkswaterstaat) and colleagues collected the current velocity data. Johan Craeymeersch of Wageningen Marine Research, Yerseke, helped with taxonomic rules of macrofauna. Sampling for this study was funded by Rijkswaterstaat, Zeeland, in the framework of the MONEOS Westerschelde programme. We thank Dick J. de Jong, Marco Schrijver and Silvana Ciarelli of Rijkswaterstaat, Directie Zeeland (ZD), and Saa Henry Kabuta of Rijkswaterstaat (WVL) for discussions and for commenting on earlier versions of the manuscript. Data supporting this article are available from doi: 10.4121/uuid:dba6c982-7187-4b8c-a597-a9bb4a8d2d6e 


\section{LITERATURE CITED}

Armonies WA, Hellwig-Armonies M (1992) Passive settlement of Macoma balthica spat on tidal flats of the Wadden Sea and subsequent migration of juveniles. Neth J Sea Res 29:371-378

Ashley GM (1990) Classification of large-scale subaqueous bedforms: a new look at an old problem. J Sedimentary Petrol 60:160-172

Baptist MJ, van Dalfsen J, Weber A, Passchier S, van Heteren S (2006) The distribution of macrozoobenthos in the southern North Sea in relation to meso-scale bedforms. Estuar Coast Shelf Sci 68:538-546

Barros F, Underwood AJ, Archambault P (2004) The influence of troughs and crests of ripple marks on the structure of subtidal benthic assemblages around rocky reefs. Estuar Coast Shelf Sci 60:781-790

Bolam SG (2011) Burial survival of benthic macrofauna following deposition of simulated dredged material. Environ Monit Assess 181:13-27

Clarke KR, Warwick RM (2001) Change in marine communities: an approach to statistical analysis and interpretation, 2nd edn. Plymouth Marine Laboratory, Plymouth

Dalrymple RW, Knoght RJ, Lambiase JJ (1978) Bedforms and their hydraulic stability relationship in a tidal environment, Bay of Fundy, Canada. Nature 275:100-104

Davidson IC, Crook AC, Barnes DKA (2004) Macrobenthic migration and its influence on the intertidal diversity dynamics of a meso-tidal system. Mar Biol 145:833-842

de Jong JW (2012) Toelichting bij de geomorfologische kartering Westerschelde 2011, op basis van false colour luchtfoto's 1:15000. Bureau Waardenburg, Culemborg

Elliott M, Quintino V (2007) The estuarine quality paradox, environmental homeostasis and the difficulty of detecting anthropogenic stress in naturally stressed areas. Mar Pollut Bull 54:640-645

Gingold R, Ibarra-Obando SE, Rocha-Olivares A (2011) Spatial aggregation patterns of free-living marine nematodes in contrasting sandy beach micro-habitats. J Mar Biol Assoc UK 91:615-622

Grant J (1981) Sediment transport and disturbance on an intertidal sandflat: infaunal distribution and recolonization. Mar Ecol Prog Ser 6:249-255

Grantham BA, Eckert GL, Shanks AL (2003) Dispersal potential of marine invertebrates in diverse habitats. Ecol Appl(Suppl)13:S108-S116

Günther CP (1992) Dispersal of intertidal invertebrates: a strategy to react to disturbances of different scales? Neth J Sea Res 30:45-56

Hinchey EK, Schaffner LC, Hoar CC, Vogt BW, Batte LP (2006) Responses of estuarine benthic invertebrates to sediment burial: the importance of mobility and adaptation. Hydrobiologia 556:85-98

Idier D, Astruc D, Hulscher SJMH (2004) Influence of bed roughness on dune and megaripple generation. Geophys Res Lett 31:L13214

Kers AS, Walburg L, Bakker J, Daane AH and others (2013) Dienstbeschrijving Zoute ecotopenkarteringen. Rijkswaterstaat CIV/ZD, Delft

Kranz PM (1974) The anastrophic burial of bivalves and its paleoecological significance. J Geol 82:237-265

Larcombe P, Jago CF (1996) The morphological dynamics of intertidal megaripples in the Mawddach Estuary, North Wales, and the implications for palaeoflow reconstructions. Sedimentology 43:541-559

Levinton J, Kelaher B (2004) Opposing organizing forces

Editorial responsibility: Erik Kristensen,

Odense, Denmark of deposit-feeding marine communities. J Exp Mar Biol Ecol 300:65-82

Lytle DA, Poff NL (2004) Adaptation to natural flow regimes. Trends Ecol Evol 19:94-100

* Maria TF, Vanaverbeke J, Gingold R, Esteves AM, Vanreusel A (2013) Tidal exposure or microhabitats: What determines sandy-beach nematode zonation? A case study of a macrotidal ridge-and-runnel sandy beach in Belgium. Mar Ecol 34:207-217

Markert E, Kröncke I, Kubicki A (2015) Small scale morphodynamics of shoreface-connected ridges and their impact on benthic macrofauna. J Sea Res 99:47-55

*Norkko A, Cummings VJ, Thrush SF, Hewitt JE, Hume T (2001) Local dispersal of juvenile bivalves: implications for sandflat ecology. Mar Ecol Prog Ser 212:131-144

*Passchier S, Kleinhans MG (2005) Observations of sand waves, megaripples, and hummocks in the Dutch coastal area and their relation to currents and combined flow conditions. J Geophys Res 110:F04S15

* Ramey PA, Grassle JP, Grassle JF, Petrecca RF (2009) Smallscale, patchy distributions of infauna in hydrodynamically mobile continental shelf sands: Do ripple crests and troughs support different communities? Cont Shelf Res 29:2222-2233

Reineck HE, Singh IB (1980) Depositional sedimentary environments. Springer, Berlin

Shepherd SA (1983) The epifauna of megaripples: species' adaptations and population responses to disturbance. Austral Ecol 8:3-8

Southard JB, Boguchwal LA (1973) Flume experiments on transition from ripples to lower flat bed with increasing sand size. J Sediment Petrol 43:1114-1121

* Van Colen C, De Backer A, Meulepas G, van der Wal D, Vincx M, Degraer S, Ysebaert T (2010) Diversity, trait displacements and shifts in assemblage structure of tidal flat deposit feeders along a gradient of hydrodynamic stress. Mar Ecol Prog Ser 406:79-89

*van der Wal D, Herman PMJ, Forster RM, Ysebaert T and others (2008) Distribution and dynamics of intertidal macrobenthos predicted from remote sensing: response to microphytobenthos and environment. Mar Ecol Prog Ser 367:57-72

*van der Wal D, Lambert GI, Ysebaert T, Plancke YMG, Herman PMJ (2017) Hydrodynamic conditioning of diversity and functional traits in subtidal estuarine macrozoobenthic communities. Estuar Coast Shelf Sci 197:80-92

van Dijk TAGP, van Dalfsen JA, Van Lancker V, van Overmeeren RA, van Heteren S, Doornenbal PJ (2012) Benthic habitat variations over tidal ridges, North Sea, the Netherlands. In: Harris PT, Baker EK (eds) Seafloor geomorphology as benthic habitat. Elsevier, London, p 241-249

* Ysebaert T, Herman PMJ, Meire P, Craeymeersch JAM, Verbeek H, Heip CHR (2003) Large-scale spatial patterns in estuaries: estuarine macrobenthic communities in the Schelde estuary, NW Europe. Estuar Coast Shelf Sci 57:335-355

* Zonneveld JP, Gingras MK, Hodgson CA, McHugh LP, Meyers RA, Schoengut JA, Wetthuhn B (2014) Biotic segregation in an upper mesotidal dissipative ridge and runnel succession, west Salish Sea, Vancouver Island, British Columbia. In: Hembree DI, Platt BF, Smith JJ (eds) Experimental approaches to understanding fossil organisms. Springer, Dordrecht, p 169-194

Zühlke R, Reise K (1994) Response of macrofauna to drifting tidal sediments. Helgol Meeresunters 48:277-289

Submitted: May 4, 2017; Accepted: October 18, 2017

Proofs received from author(s): December 13, 2017 